\title{
PUBLIC HEALTH:
}

\section{The Fournal of the Fncorporated Fociety of Sildedical Officers of ibealth.}

VoL. XVIII. No. 2.

NOYEMBER, 1905.

\section{MEASLES : ITS PREVALENCE AND MORTALITY IN ABERDEEN.}

By GEORGE N. WILSON, M.D., D.P.H.

Public Health Department, City of Aberdeen.

THE following statistical investigation has been undertaken at the suggestion and under the guidance of the Medical Officer of Health of Aberdeen, who has given me full access to the material.

Measles is probably the most universal of human zymotics in this country, and as the case mortality, though greatly less than that of some more dreaded zymotics, is not inconsiderable, the total number of deaths in the course of years is so great as to demand for the disease a foremost place in the consideration of hygienists, and of the community.

In Aberdeen, within the last ten years measles caused more deaths than any other single zymotic, and even more than all the other zymotics taken together, if whooping cough be excluded.

The compulsory notification of measles has, as yet, been tried in only a few towns, of which Aberdeen is one; and as the data obtainable from such notification have not yet anywhere, so far as I am aware, been fully tabulated and analysed, I have undertaken this task for the City of Aberdeen, in hope that the results, which have been worked out with all proper care, may be of permanent value.

As early as 1881 the Corporation of Aberdeen obtained powers to compel the notification of infectious diseases, including measles and whooping cough.

Under the Aberdeen local Act of 1881, notification by the medical attendant only was required. After the passing of the Infectious Disease (Notification) Act, 1889, the Town Council adopted it in 1891, in order to obtain the advantage of dual notification-that is, by the medical attendant and by the householder. After a report from the 
Medical Officer of Health, the compulsory notification of measles and whooping cough was stopped in February, 1903, as experience appeared to show that the benefits scarcely justified the large cost.

There has thus been a continuous notification in Aberdeen of all cases of measles since the end of 1881 to the beginning of 1903 .

I purpose dealing with the material obtainable for the twenty years 1883 to 1902 , inclusive, and on similar lines to a paper on Whooping Cough in Aberdeen, prepared by the late Dr. James S. Laing, in 1902.* No doubt a question may arise as to the completeness of the record of cases of measles during these years. It must be admitted that the notification of any disease is rarely absolutely complete. Some cases are unrecognized, and others may be wilfully concealed. The Aberdeen records cannot, therefore, pretend to scientific completeness, but they represent every case brought to the notice of the Medical Officer of Health and his staff, under a system of compulsory notification, with a penalty for failure. And it may be added that the compulsory powers were rigidly applied throughout the whole period, prosecution having, when required, been instituted against defaulters.

\section{Population of Aberdeen.}

As the cases and deaths are for the most part calculated in relation to the population of the City, so as to eliminate any possible error which may arise from the growth of the population not being sufficiently kept in view, I may state that I have adopted for each year the population given by the Registrar General in his returns, though modifying it in certain instances where the revelations of a subsequent census rendered modification necessary. The population of Aberdeen in 1881 was 105,538 ; in $1891,123,348$; and in $1901,154,295$. In the first half of the twenty years to which this investigation applies, the average population was 117,011 , and in the second half 143,039 .

Attack-Incidence (Morbidity) of Measles.

I.-In respect of Time and Season.

II.-In respect of Age and Sex.

III.-Second Attacks.

IV.-Comparison with Whooping Cough.

I.-In respect of Time and Season.

A. TIME.

(Table I.; Chart I.)

From the commencement of 1883 until the end of 1902, there were notified in Aberdeen 40,374 cases of measles (see Table I) which were divided between the sexes as follows:--

$$
\begin{array}{lcccc}
\text { Males } & \ldots & \ldots & \ldots & 20,287 \\
\text { Females } & \ldots & \ldots & \ldots & 20,087
\end{array}
$$

* Published in Public Health, July, 1902, vol. xiv., p. 584. 


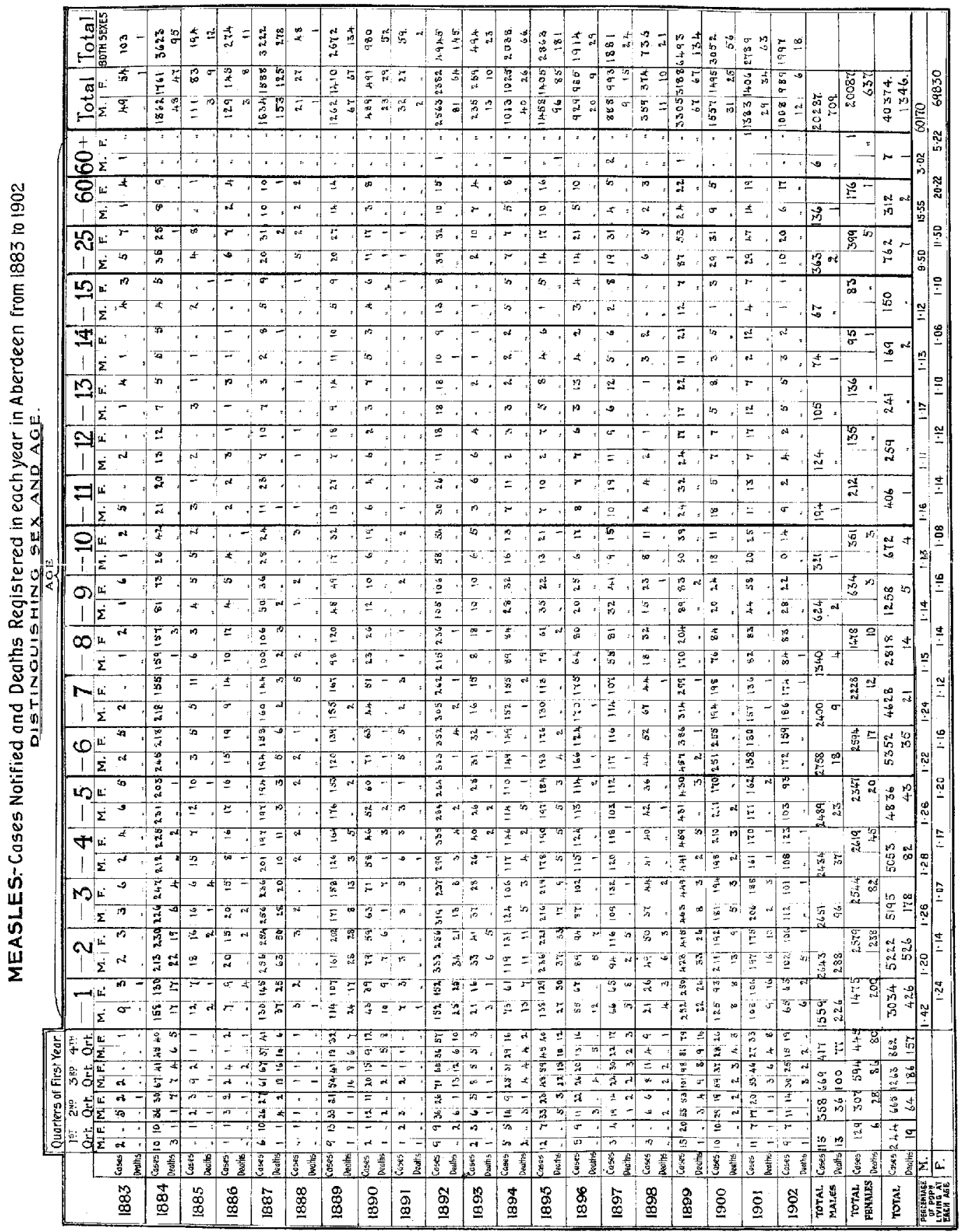


For the two halves of the period the figures were :-

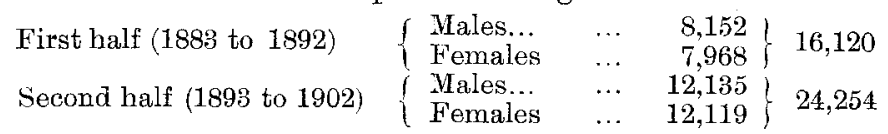

These figures show a large increase of cases in the second decennial period; and, even after allowance has been made for the considerable growth of population, it is evident that measles was more prevalent in the later than in the earlier decennium. Perhaps it was to some extent more apparent than real, from an increasing thoroughness in notification. Even if this should be so, it does not greatly modify the chief conclusions to be drawn from my statistical inquiry.

Chart I shows in graphic form the monthly attack incidence of measles from 1883 to 1902 , the cases being calculated per 100,000 of population. The peaks indicate the times of highest prevalence, and the troughs the periods or intervals of quiescence. The upright lines mark off the commencement of each year, and the dots represent each month of the year.

It will be observed that the height of the highest peak in an epidemic does not always indicate the extent or mass of the epidemic. Some epidemics rise quickly to a great height, and fall as quickly, while others, which do not rise so high, cover a longer period of time-e.g., the epidemic of 1892 attained the giant height of 1,613 per 100,000 of population in three months, and fell almost to zero in four months, thus covering a period of seven months, whereas the epidem of 1900 rose to 694 per 100,000 of population in two months, but took eleven months to fall to zero. The epidemic of 1900, as a matter of fact, represented more cases than that of 1892 . The same is true of a comparison of 1887 and 1884. The epidemic in the latter year, although the lower in height on the chart, represents considerably more notified cases.

In the same chart one notes a marked cyclical change in the epidemic peaks, the tendency of which is obviously biennial. This epidemic periodicity, however, is more strongly marked in the second than the first half. In the latter also the intervals are slightly shorter and more regular than in the former.

The chart also distinctly suggests a periodicity among the epidemic years themselves, a specially high epidemic rise showing itself about every sixth year, or at every third epidemic.

It would also appear as if the longer the interval, the greater is the height attained by the succeeding epidemic wave. This is instanced in the very high epidemic peak of 1892 , preceded by a long interval of quiescence, and in the very low wave of 1890 , with scarcely any preceding interval. This is precisely what we would expect to find. 
It may also be proper to direct attention to the increased numbers notified in the second ten years of the period under discussion, as possibly indicating a third cyclical change in the form of a long-period prevalence wave. Chart XI. which shows graphically the yearly mortality per 100,000 of population for Aberdeen and other large towns for 45 years, also shows evidence of such a cyclical change. This is common to almost all the towns compared in the chart, and may be returned to at a later stage.

Such an imposition of wave upon wave-smaller ones upon larger ones-is what might be expected from physical analogy.

\section{B. SEASON.}

\section{(Table II. ; Chart II.)}

In Chart II. is represented the average attack-incidence of measles per 100,000 of population in each of the twelve months of the year, based on the notification returns for the twenty years ending 1902 (see also Table II.).

Measles is a distinctly seasonal disease, and, as will be seen from an examination of Charts I. and II., it generally reaches its highest prevalence in the colder months of the year. This, however, is subject to considerable variation, as Chart $I$. shows that the epidemic may reach its height as early as September or as late as May.

Looking at the monthly averages represented in Chart II., one observes, besides the general rise in the colder months, two maxima, one-the higher-in December, and the other - the lower-in March, with a very well-marked minimum in August, when the cases are less than one-tenth of the number in December.

If the averages for the months in the first half of the twenty years are alone taken, a decided dip is exhibited in January, but this is not apparent in the second half, as the following table shows:-

\section{CASES OF MEASLES NOTIFIED :-}

\begin{tabular}{llll|llll}
\multicolumn{2}{c|}{ Tn the Ten Years, 1888 to 1892.} & \multicolumn{2}{|c}{ In the Ten Xears, 1893 to 1902.} \\
\hline & & & & & & \\
\hline Jamuary & $\ldots$ & $\ldots$ & 506 & January & $\ldots$ & $\ldots$ & 4,501 \\
February & $\ldots$ & $\ldots$ & 1,127 & February & $\ldots$ & $\ldots$ & 4,242 \\
March & $\ldots$ & $\ldots$ & 2,027 & Maxch & $\ldots$ & $\ldots$ & 3,473 \\
April $\ldots$ & $\ldots$ & $\ldots$ & 1,169 & April $\ldots$ & $\ldots$ & $\ldots$ & 1,293 \\
May $\ldots$ & $\ldots$ & $\ldots$ & 1,065 & May $\ldots$ & $\ldots$ & $\ldots$ & 726 \\
June $\ldots$ & $\ldots$ & $\ldots$ & 746 & June $\ldots$ & $\ldots$ & $\ldots$ & 589 \\
July $\ldots$ & $\ldots$ & $\ldots$ & 593 & July $\ldots$ & $\ldots$ & $\ldots$ & 460 \\
August & $\ldots$ & $\ldots$ & 833 & August & $\ldots$ & $\ldots$ & 256 \\
September & $\ldots$ & $\ldots$ & 1,645 & September & $\ldots$ & $\ldots$ & 339 \\
October & $\ldots$ & $\ldots$ & 2,690 & October & $\ldots$ & $\ldots$ & 1,183 \\
November & $\ldots$ & $\ldots$ & 2,530 & November & $\ldots$ & $\ldots$ & 2,682 \\
December & $\ldots$ & $\ldots$ & 1,689 & December & $\ldots$ & $\ldots$ & 4,510 \\
\hline
\end{tabular}




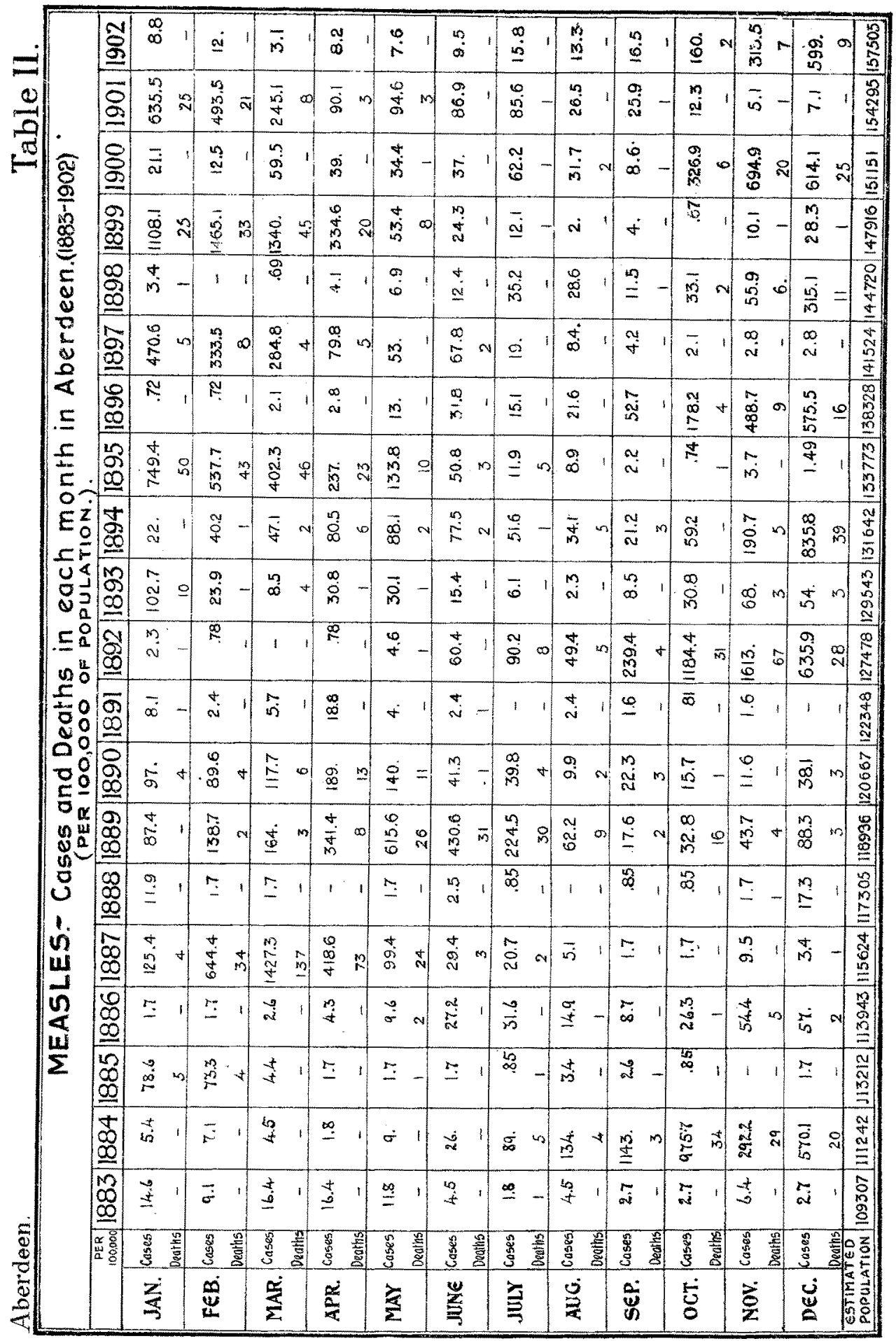


Aberdeen.

Chart II.

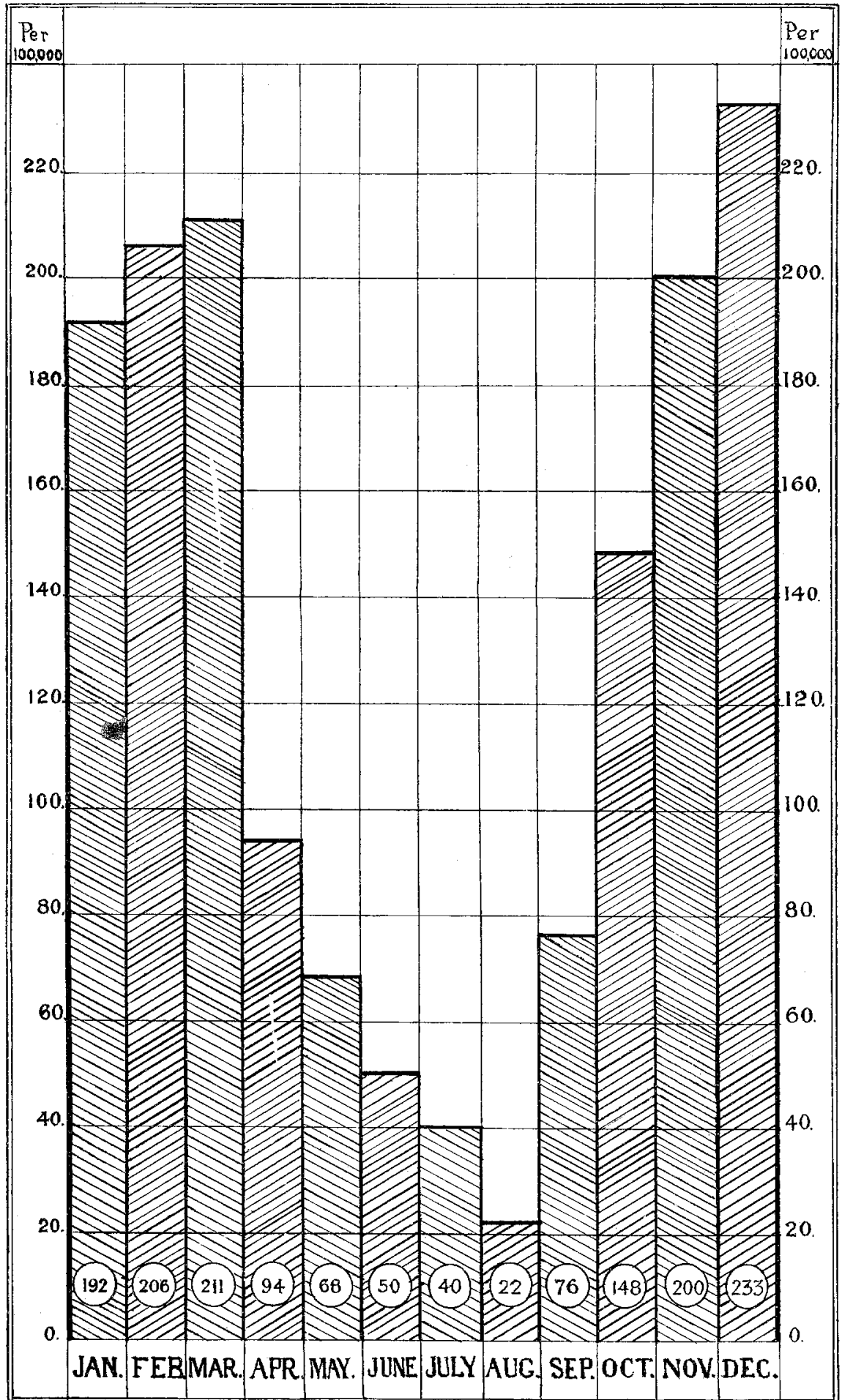

MEASLES.- Number of attacks per 100,000 of Population in each of the twelve months of the year (average of 20 years $-1883-1902$ ) 
Aberdeen.

Chart III.

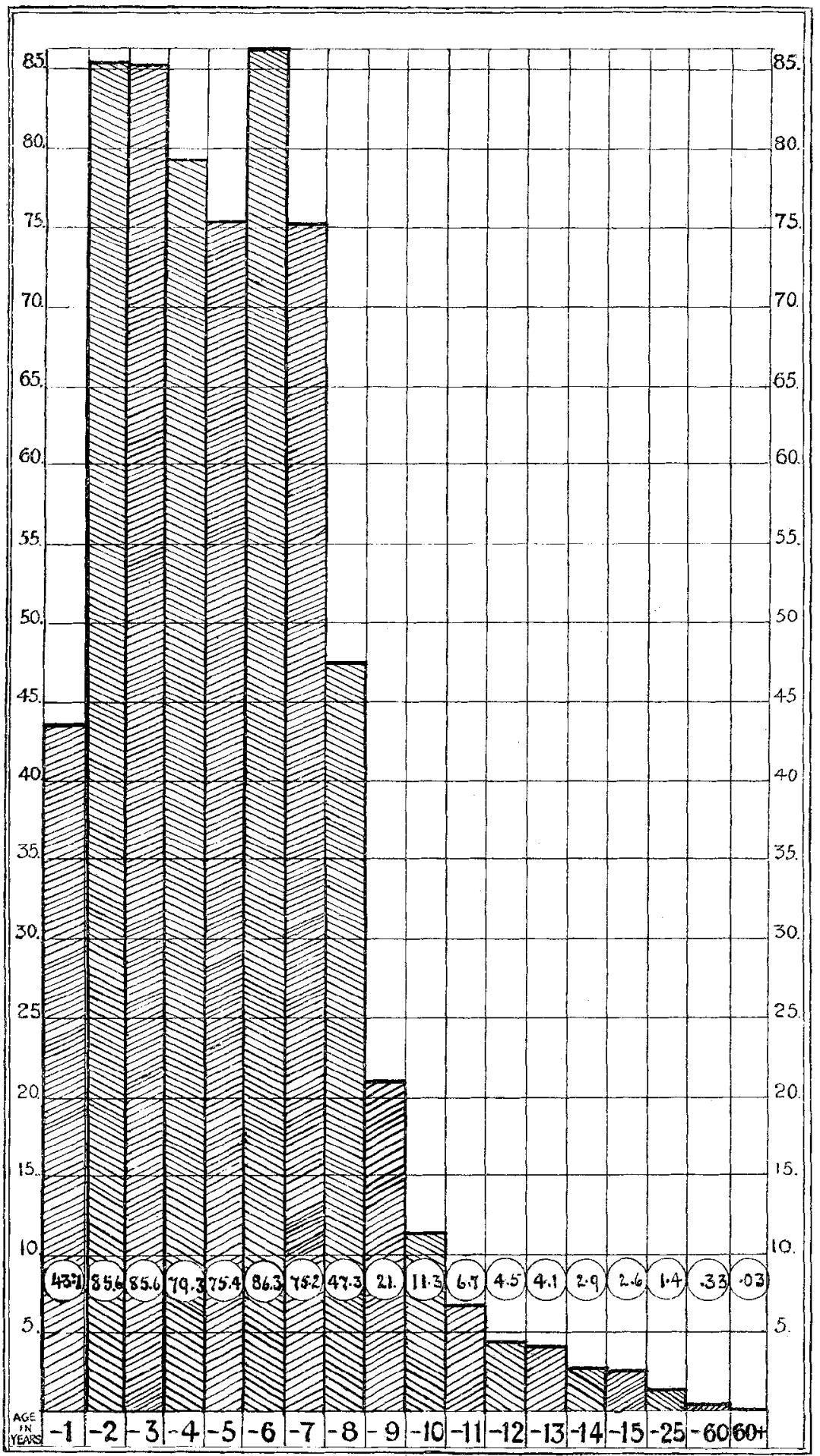

MEASLES- Atracks per 1000 of Population living at each age, (average of 20 years-1883-1902) 
A similar chart for whooping cough to that here given (Chart II.) for measles, accompanied the paper of Dr. James S. Laing, and it may be of interest to recall that the maximum of prevalence of whooping cough was found to be in April, and the minimum in September; that the maximum was only about three times the minimum; and that the ascent from the minimum to the maximum was slow.

\section{II.-Incidence in respect of Age and Sex.}

\section{A. AGE (SEXES COMBINED).}

(Table $1 . ;$ Chart III.)

Chart III. shows for a period of twenty years the average number of cases of measles notified annually per 1,000 of population living at different ages, the sexes being taken together. The various ages are dealt with individually up to fifteen years. The remaining ages, being of less importance in this connection, are divided into three age-groups, viz. : fifteen to twenty-five, twenty-five to sixty, and sixty and over.

The incidence of attack is heaviest-and about equally heavyamong children of the sixth, second, and third years of life, being, respectively, $86 \cdot 3,85^{\circ} 6$, and $85 \cdot 6$ per 1,000 living at these ages. Next in order come children in the fourth year of age, their figure standing at 79.3 per 1,000 , followed by children in the fifth and seventh years of age, whose attack rates are, respectively, 75.4 and 75.2 . These are the years of large incidence. Next come two years with a moderate incidence, namely, the eighth year of age, with an attack rate of $47 \cdot 3$ per 1,000 living, and the first year with a rate of $43 \cdot 7$ per 1,000 .

At a still lower level comes the ninth year, with a rate of 21 per 1,000 living; and from this to the age of fifteen years, with a rate of $2 \cdot 6$ per 1,000 living, the fall is rapid and in the order of the increase of age. The age group of fifteen to twenty-five years has an attack incidence of 1.4 per 1,000 living; and only seven cases are notified in twenty years as having occurred in persons over sixty years of age.

The lessening liability to attack in the higher ages is, of course, almost entirely due to so many at those ages being protected by a previous attack in childhood.

The chief conclusion from this chart is that the great bulk of children have before the completion of their eighth year taken measles, at any rate in a town like Aberdeen; and the practical inference is that it is needless in a threatened epidemic of measles to close schools in so far as children above eight years are concerned.

\section{B. AgE (SEXES SEPARATE). \\ (Table I. ; Chart IV.)}

Chart IV. deals with the attack-incidence of measles at each age, and for the sexes taken separately. 
At every age, except the sixth year of age, the liability to attack is greater in females than in males, but the difference is small.

This greater liability to attack in females is most marked in the third and fourth years of age, females having an attack-incidence of $91 \cdot 1$ and 86.1 (at these two ages), and males an incidence of 80.9 and 73.2 per 1,000. At other ages the difference of incidence between the sexes is so slight as to be negligible.

\section{III.-Second Attacks.}

The following table of second attacks shows such cases as were notified during the ten years 1893 to 1902 . It gives the total number of notified cases, the number of second attacks amongst these, and the proportion of second attacks per 1,000 cases. The number for each sex, and for the sexes combined, is given for all ages, and at different age-periodss.

The proportion of second attacks to the total cases rises steadily with the increase of age, up to the age of twenty-five. Thus for the three age-periods of $0-5$ years, $5-15$ years, and $15-25$ years, the figures for the sexes combined are $9 \cdot 6,43 \cdot 8,98 \cdot 0$ per 1,000 cases, respectively. Above the age of twenty-five years, the figure is 10 per 1,000 .

At every age-group, except fifteen to twenty-five, females suffer more frequently than males from second attacks. This is also the case at "all ages," where the rate for females is 28.5 , and for males $20 \cdot 8$ per 1,000 of total notified cases.

Why the second attacks should be greater amongst males than females at the age-group of fifteen to twenty-five, it is difficult to say, especially as females of this age, being more among younger children than boys are, should be more exposed to infection.

SECOND ATTACKS,-TEN YEARS, 1893-1902.

\begin{tabular}{|c|c|c|c|c|c|c|c|c|c|c|c|}
\hline \multirow{3}{*}{ AGE-PERIOD, } & \multicolumn{3}{|c|}{ MALES. } & \multicolumn{3}{|c|}{ FEMACES. } & \multicolumn{3}{|c|}{ BOTH SEXES. } & \multirow{2}{*}{\multicolumn{2}{|c|}{$\begin{array}{l}\text { Deaths } \\
\text { among } \\
\text { Cases } \\
\text { under } \\
\text { Second } \\
\text { Attack. }\end{array}$}} \\
\hline & \multirow{2}{*}{ 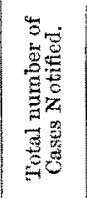 } & \multirow{2}{*}{ 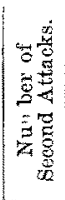 } & \multirow{2}{*}{ 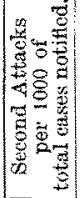 } & \multirow{2}{*}{ 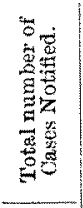 } & \multirow{2}{*}{ 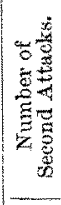 } & \multirow{2}{*}{ 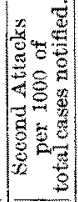 } & \multirow{2}{*}{ 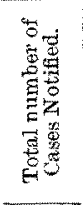 } & \multirow{2}{*}{ 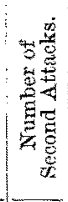 } & \multirow{2}{*}{ 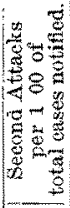 } & & \\
\hline & & & & & & & & & & $\frac{\dot{d}}{3}$ & 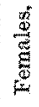 \\
\hline Undex 5 years & 7,071 & 60 & $8 \cdot 4$ & 7,041 & 76 & 107 & 14,112 & 136 & 96 & 3 & 4 \\
\hline $5-15$ & 4,757 & 169 & 35.5 & 4,727 & 247 & 522 & 9,484 & 416 & $43 \cdot 8$ & 0 & 0 \\
\hline $15-25$ & 217 & 24 & $110 \cdot 6$ & 242 & 21 & 867 & 459 & 45 & 98.0 & 0 & 0 \\
\hline 25 years and upwards & 90 & 100 & $0 \cdot 0$ & 109 & 2 & 183 & 109 & 2 & $10^{\circ}$ & 0 & 0 \\
\hline All ages & $\mid 12,135$ & 253 & $20 \cdot 8^{1}$ & $12,119^{\prime}$ & 346 & $28 \cdot 5$ & 24,254 & 599 & $24 \cdot 6$ & 3 & 4 \\
\hline
\end{tabular}




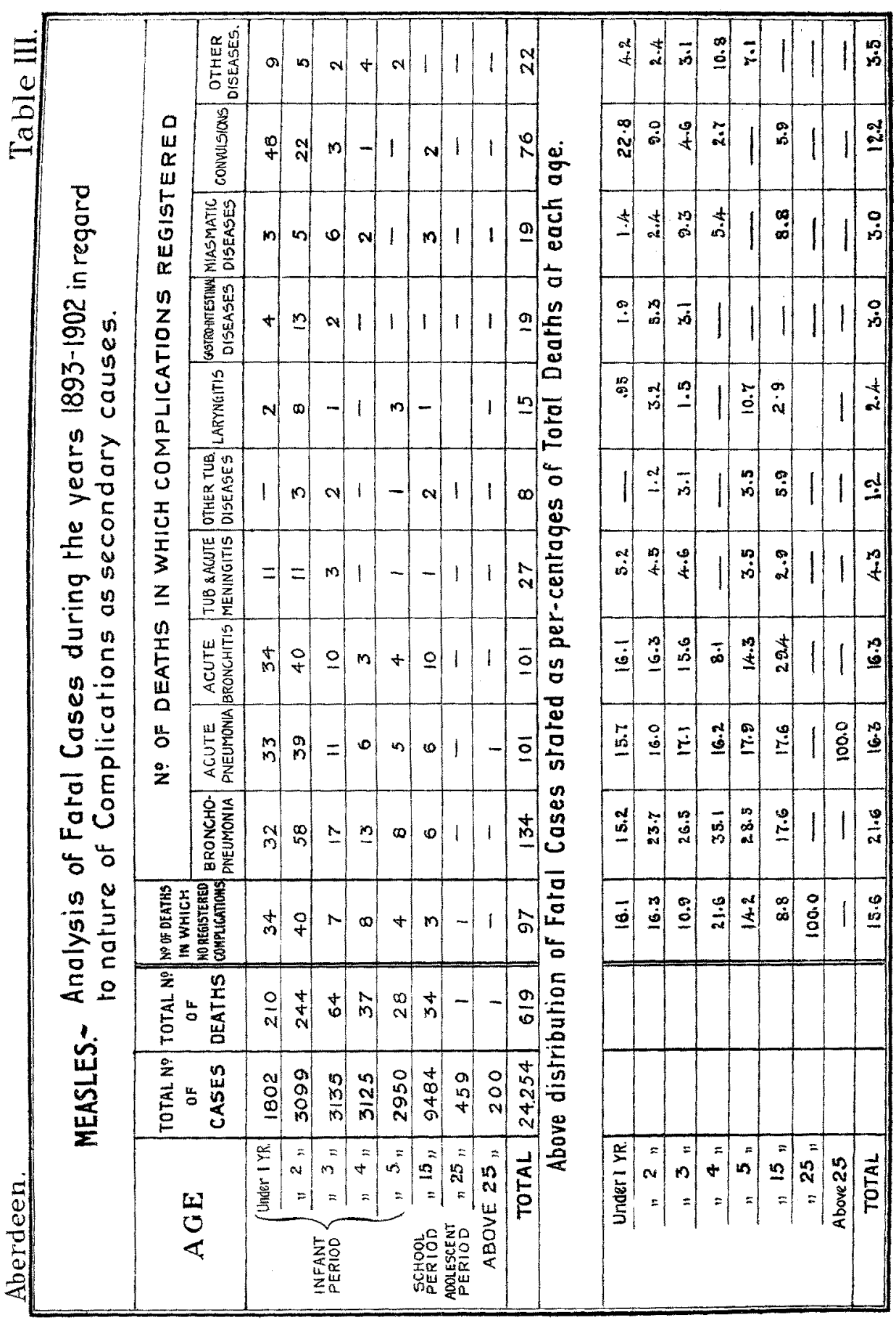




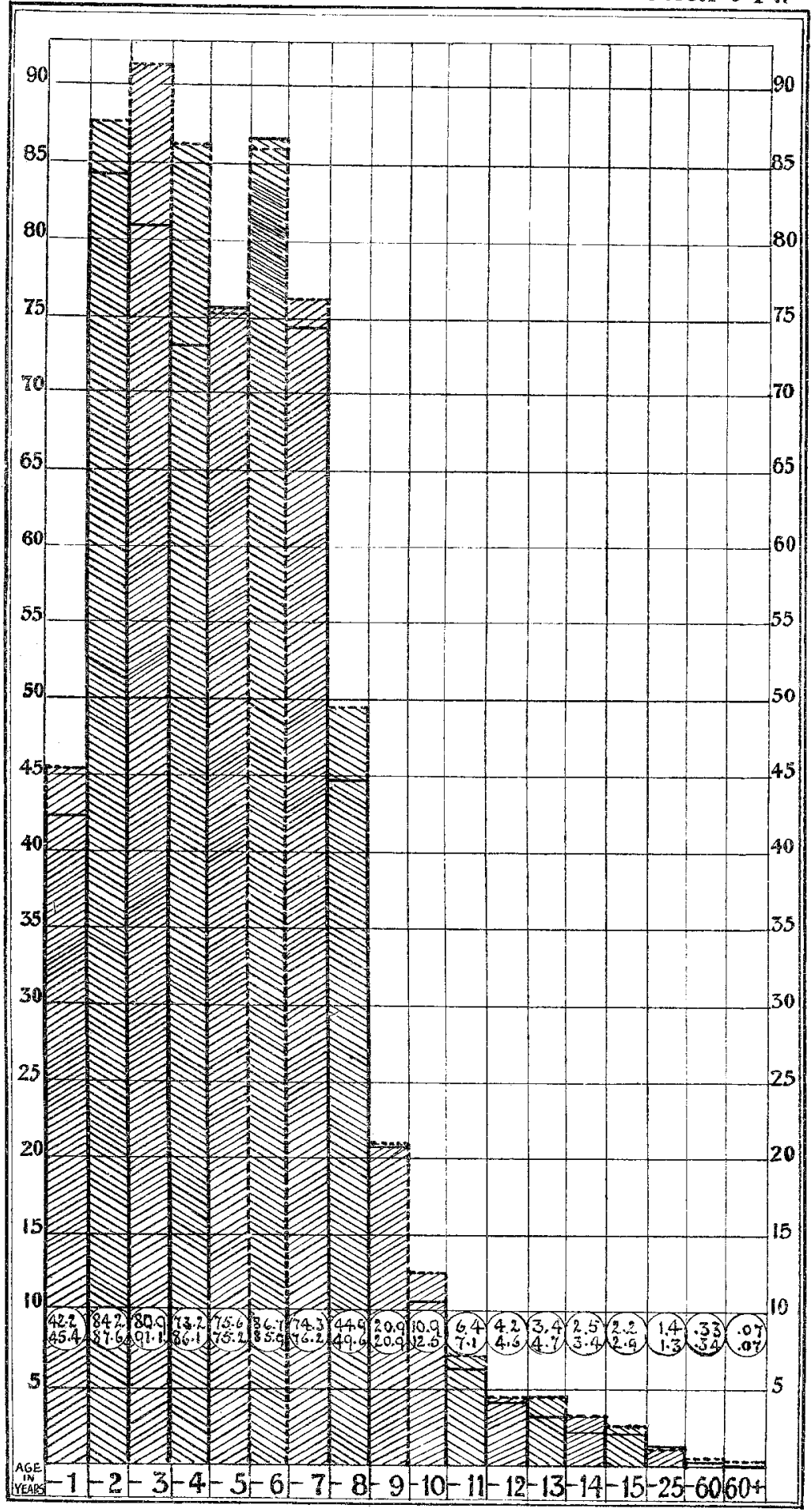

MEASLES.- Atracks per 1000 of Population at each age and of each sex.(average of 20 years-1883-1902).

$$
\text { MALES FEMALES }
$$


THIRD ATTACKS.

There were recorded thirteen cases of third attacks during the ten years, viz., in five males and eight females. Two of these were under five years of age, ten under fifteen, and one was fifteen years of age. Third attacks thus stand in the proportion of 21.8 per 1,000 second attacks.

The value of the records of second and third attacks is probably not great, as it is impossible to eliminate the error due to German measles being mistaken for measles. In every case of measles, inquiry was invariably made as to a previous attack, a question as to this being included in the schedule of the visiting inspector.

\section{IV.-Association of Measles and Whooping Cough. (Chart I.)}

Chart I., besides showing the monthly incidence for measles for twenty years, also shows the monthly incidence of whooping cough for the same period, on the same scale, and stated per 100,000 of population.

Epidemics of measles and whooping cough so frequently follow each other that it has been generally supposed that the former predisposes to, or in some way prepares the way for, the latter.

If, as stated, measles precedes whooping cough, the line showing the decline of the measles epidemic wave should be crossed by the rising line of the whooping cough epidemic wave. This, as a matter of fact, occurs only in one instance, viz., in 1895 . Indeed, it will be seen that the declining wave line of whooping cough is more often overlapped by the rising epidemic wave line of measles, as if whooping cough were the precursor of measles. In most cases the peak of the measles epidemic is usually considerably closer to the peak of the preceding than to that of the succeeding whooping cough epidemic.

Both diseases tend to be biennial in their epidemic periodicity, and alternate with considerable regularity.

\section{Mortality from Measles. \\ (Tables $I$. and II.; Charts V. and XI.)}

Chart V. exhibits graphically the death-rate from measles per 100,000 of population for each month of the twenty years-1883 to 1902. In its main features this chart follows closely Chart I., which shows the monthly attack-incidence for the same period.

The chart shows a fairly steady decline in the mortality since about 1887. The peaks of mortality are decidedly lower as the years progress. The average annual mortality for the first ten years is 62.4 per 100,000 of population, while for the second ten years it is 43.0 per $100,000-$ a reduction of almost one-third. 
Chart XI. gives the mortality from measles since 1856, but the mortality is represented for each year, and not for each month, as in Chart VI. Reference will be made to this chart at a later stage.

\section{Case-Mortality in Measles.}

I.--In respect of Time and Season.

II.--In respect of Age and Sex.

III.--In relation to Attack-Incidence.

IV.--In relation to Size of House.

\section{1.-Case-Mortality in respect of Time and Season.}

A. TIME.

(Chart VI.)

Chart VI. represents in graphic form the progress of the casemortality in measles for the twenty years-1883 to 1902 . The deaths occurring in each quarter of the year are stated as a percentage of the cases notified in the same quarter. For purposes of comparison the attack-incidence per 1,000 of population for each quarter is also given.

The chart shows that the case-mortality has been undergoing a considerable diminution in the course of the twenty years. In the first five years it was 5.3 per cent; in the second five years, 3.8 per cent; in the third five years, 3.5 per cent ; and in the last five years, 1.9 per cent. As all deaths from measles have presumably throughout the whole period been registered, while, probably, notification of sicknesses was less complete in the earlier than in the later years, a certain proportion of the fall in the case-mortality may be more apparent than real ; but when allowance is made for this there remains a sufficient margin of difference to justify the inference that there has been a real decrease in the case-mortality.

The very irregular height of the case-mortality is noteworthy, varying from 0 to 25 per cent. It will be observed that the highest peaks of case-mortality in the chart coincide for the most part with a waning attack-incidence, and are no doubt partly due to some of the numerous cases in a preceding quarter ending fatally in the next quarter, when the cases notified were few in number. But as the chart is prepared for quarters in place of months, in order to assist in avoiding the distortion due to this cause, it is probably a legitimate inference that epidemics of measles are more fatal during their decline than during their rise. Some of the highest peaks of case-mortality occur in interepidemic periods, and should not have too much importance attached to them, owing to the smallness of the numbers to which they apply.

It is also to be remarked that some of the largest epidemics-for example, in 1892-93 and 1898-99-have had a very low case-mortality. 


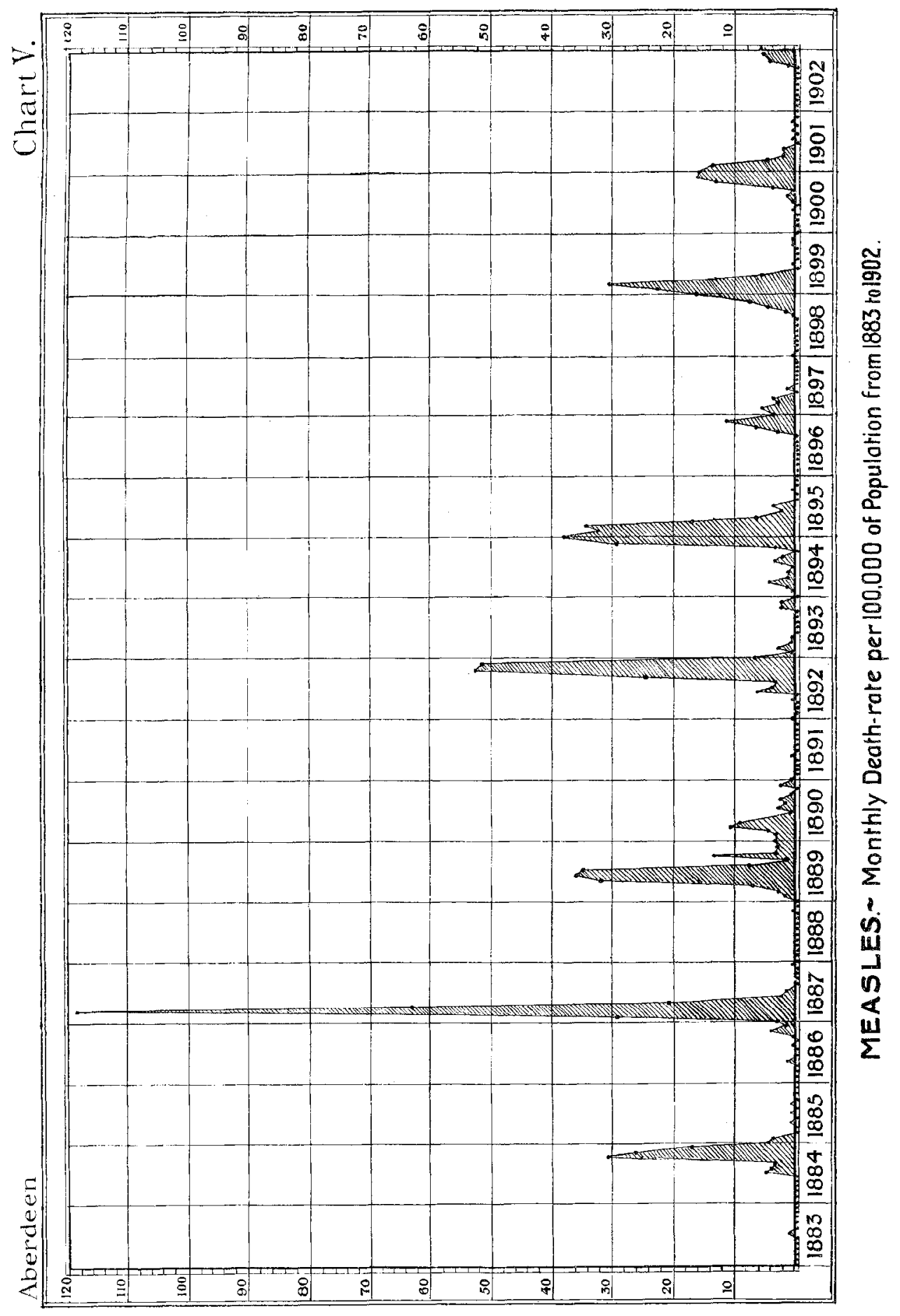




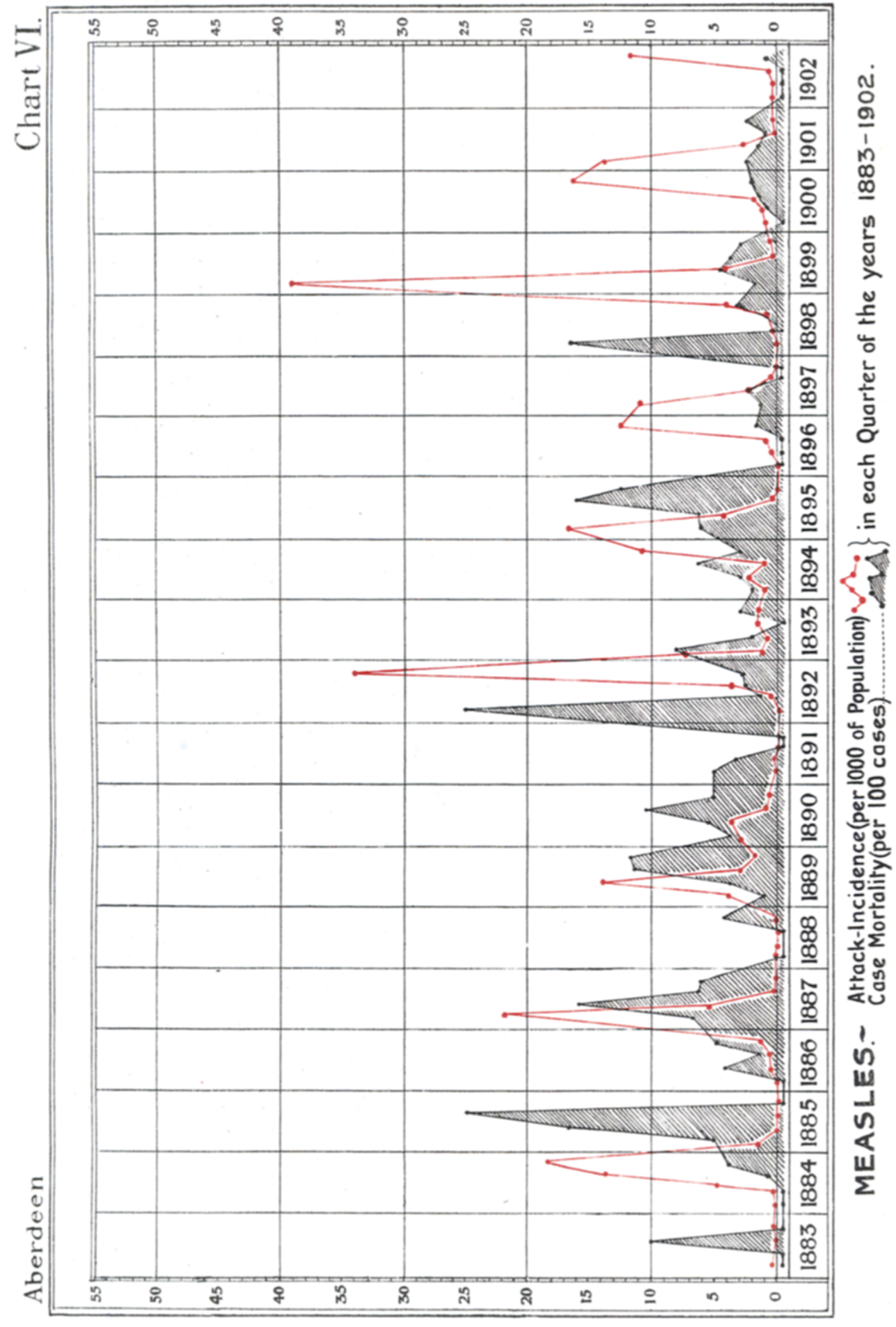




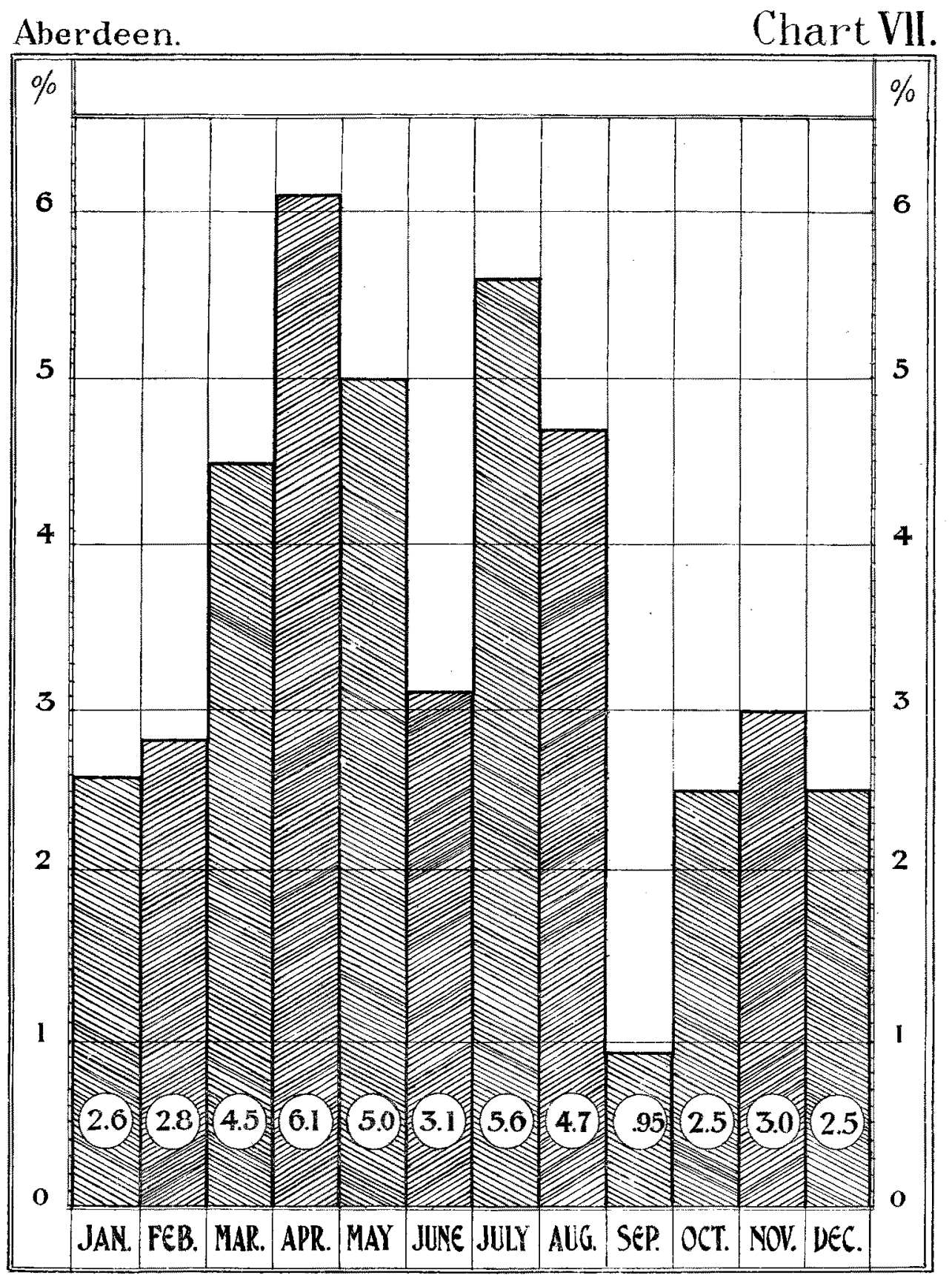

\begin{tabular}{|c|c|c|c|c|c|c|c|c|c|c|c|c|c|}
\hline CASES & 5007 & 5369 & 5500 & 2462 & 1791 & 1335 & 1053 & 589 & 1984 & 3873 & 5212 & 6199 & 40374 \\
\hline DEATHS & 131 & 151 & 255 & 152 & 90 & 43 & 60 & 28 & 19 & 98 & 158 & 161 & 1346 \\
\hline
\end{tabular}

MEASLES:- Case-Mortality Dearhs per 100 cases in each of the twelve months of the year, (average of 20 years-1883-1902.) 
Aberdeen.

ChartVIII.

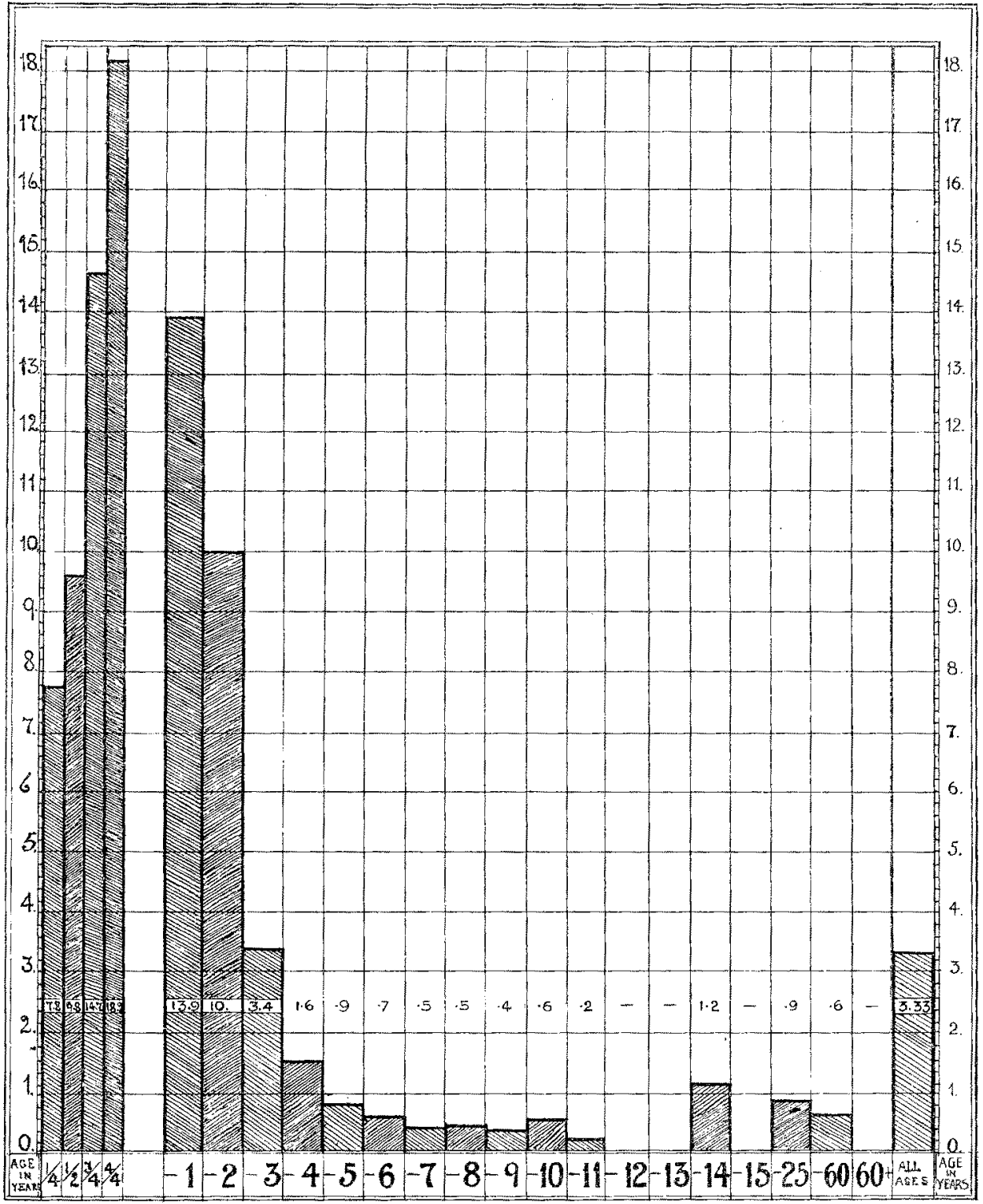

TOTAL

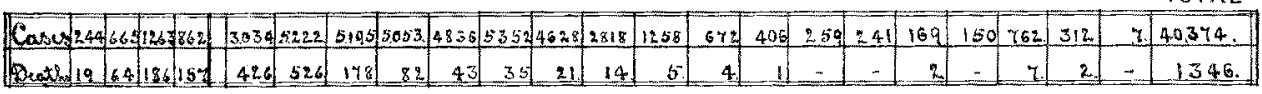

Number of Cases and Deaths clealt with at each age.

MEASLES- Case Mortality, being the deaths per 100 cases at each age (average of 20 years.) (5exes Combined) 
The general decline of the case-mortality in Aberdeen may be in part due to the greater precautions and care exercised by parents in regard to cases on account of the supervision of the Sanitary Department, consequent upon notification, and to the printed instructions provided by the Department in each case. But too much must not be claimed for this.

B. SEASON.

(Chart VII.)

Chart VII. shows graphically the average pereentage mortality among cases notified in each month of the year. It deals with 40,374 cases and 1,346 deaths, which occurred during the twenty years 1883 to 1902 . The deaths forming the case-mortality in any month are the deaths occurring among the deaths notified during the month, whether the deaths took place in that or a later month.

The ease-mortality is highest in the spring and summer months. There would appear to be in the course of the year, three maxima, viz. : in April (6.1 per cent), July ( $5 \cdot 6$ per cent), and November ( $3 \cdot 0$ per cent), with corresponding minima in September $(0.95$ per cent) December (2.5 per cent), and June ( $3 \cdot 1$ per cent).

\section{II.-Case-Mortality in respect of Age and Sex. I.-AGE (SEXES COMBINED). (Chart VIIL.)}

Chart VIII. represents the deaths from measles per 100 cases, at all ages, and at different ages, during the twenty years ending 1902, males and females being taken together.

The case-mortality is shown for each year of life up to the age of fifteen years. Above this age the cases are arranged under three age-periods-fifteen to twenty-five years, twenty-five to sixty years, and sixty years of age and upwards. The first year of life has been sub-divided to show the case-mortality in each of the four quarters.

The case-mortality for all ages taken together, and for the whole period 1883-1902, is $3 \cdot 33$ per 100 cases.

As to the case-mortality at the different ages, it is clearly seen from the chart that the first and second years constitute the period of life at which measles is by far the most fatal, the rates for these years being 13.9 and 10.0 per cent respectively. In the third year of life there is a large drop to 34 per cent, which is only a little more than one-fourth of the rate in the first year. During the fifth and sixth years of life, the mortality is between 0.5 and 1 per cent, while between the seventh and eleventh years it is about a half per cent, or less. But for two deaths in the fourteenth year, the mortality between the eleventh and fifteenth years might be regarded as nil. At the 
age-periods of $15-25$ and $2 \%$-60, the case-mortality increases somewhat, being between a half and one per cent, or about as high as in the fifth and sixth years of life. Above the age of sixty there were no deaths; but there were only seven cases.

On analysing the case-mortality within the first year of life, one finds that the rate is lowest in the first quarter, with 7.8 per cent, and rises with each quarter to 18.2 in the fourth quarter, the mortality being distinctly higher in the two later quarters than in the earlier quarters.

This chart also gives the number of cases, as well as deaths, in each quarter of the first year of life; and it will be observed that the third quarter is by far the most prolific in attacks of measles.

Dr. Laing, in his paper on whooping cough, showed that in the first year of life the greatest case-mortality is in the first quarter, thus differing from measles.

The practical conclusion from an examination of this chart is that it is of the greatest moment to prevent children taking measles during the first three years of life, but especially during the first two. If the attack could in every case be postponed till after these years, it is obvious that the reduction of the mortality from this, the most common of the zymotics, would be enormous.

Almost exactly the same observation fell to be made by Dr. Laing in his corresponding paper on whooping cough, where it was also shown that the years of high case-mortality were especially the first two years of life. It may be of interest to give the case-mortality for measles and whooping cough side by side, during the first twelve years of life

CASE-MORTALITY (PER CENT).

\begin{tabular}{|c|c|c|c|c|c|c|c|c|c|c|c|c|}
\hline Age (years)- & $x$ & 2 & 3 & 4 & 5 & 6 & 7 & 8 & 9 & 10 & 11 & 12 \\
\hline & 139 & $10 \cdot 0$ & $3 \cdot 4$ & 16 & $\cdot 9$ & $\cdot 7$ & 5 & 5 & 4 & 6 & 2 & $\cdot 0$ \\
\hline Whooping Cough & .125 & $10 \cdot 1$ & $3 \cdot 3$ & $|2 \cdot 2|$ & $1 \cdot 6$ & $\cdot 5$ & $\cdot 7$ & $\cdot 1$ & 3 & $\cdot 0$ & $\cdot 0$ & $\cdot 0$ \\
\hline
\end{tabular}

In regard to the quarters of the first year, whooping cough, differing from measles, shows the highest case-mortality in the first and second quarters, and the lowest in the third and fourth ; but, as with measles, the cases or sicknesses are most numerous in the third quarter.

$$
\begin{gathered}
\text { II.-AGE (SEXES SEPARATE). } \\
\text { (Chart } I X .)
\end{gathered}
$$

Chart IX shows the case-mortality of measles at different ages, for each of the sexes.

The average case-mortality at all ages, taken together, was greater 

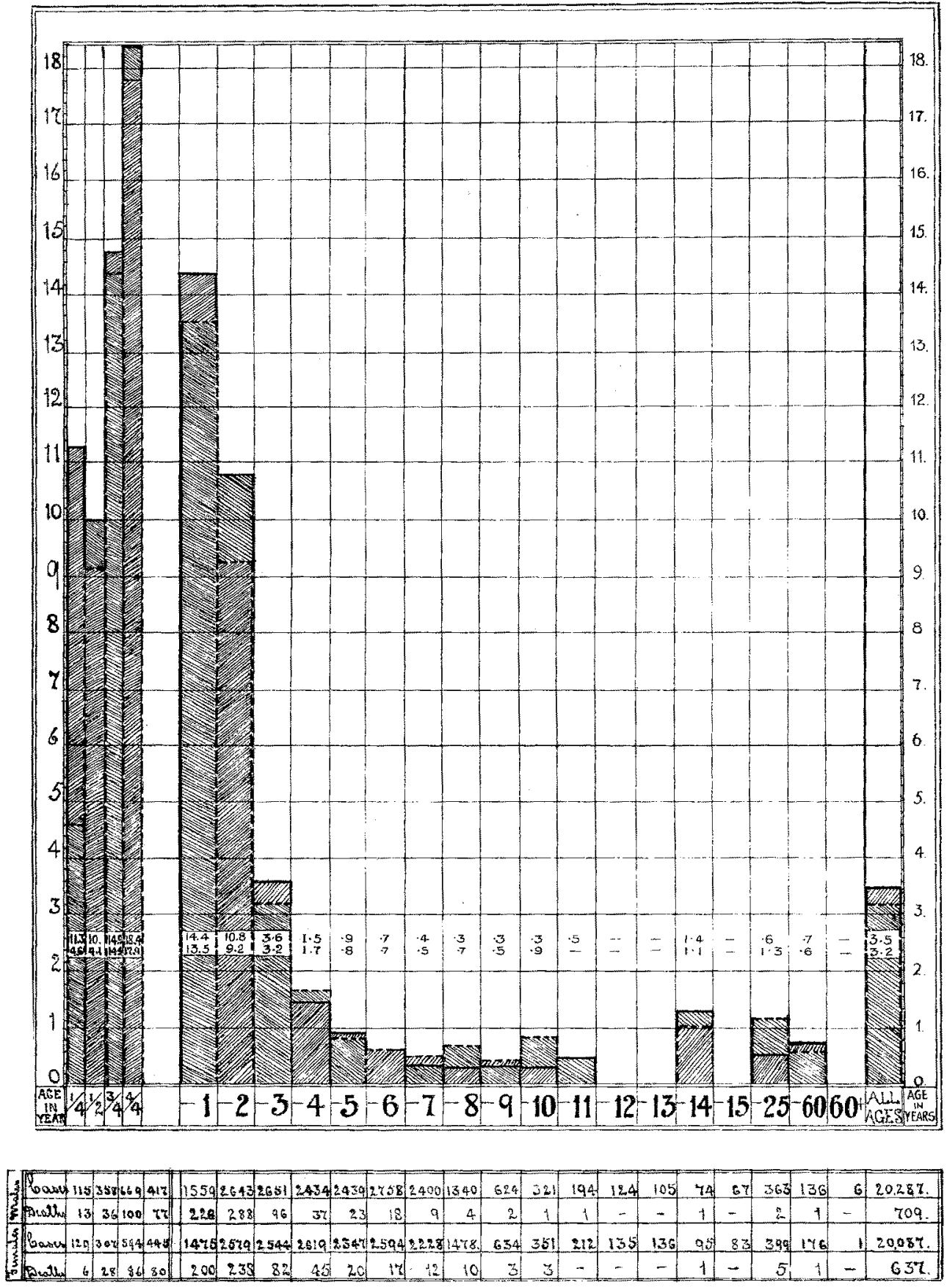

Namber of Cases and Deaths deat with at each age

MEASLES-Case Mortality, being the deaths per 100 cases at each age \& for each sex (average of 20years) 
for males than for females. For the former it was 3.5 per cent, and for the latter $3 \cdot 2$ per cent.

As regards the case-mortality at the different ages, the rate for males is distinctly greater.in the first three years. In the fourth year the female rate is slightly higher; in the fifth the male rate predominates by very little, and in the sixth the rates for both sexes are equal. In the next four years the mortality is bigher among females. At the higher ages, the deaths are so few as to render of little value any comparison at these ages.

With regard to the four quarters of the first year of life, it will be seen that in the first quarter the male case-mortality is greatly in excess of the female, being 11.3 per cent as against 4.6 per cent. In the second, third, and fourth quarters, there is not much difference between the sexes, but in each the male case-mortality is the higher.

\section{III.-Case-Mortality in Relation to Attack-Incidence. \\ (Chart VI.)}

Chart VI. was prepared in order to study the influence, if any, of a high or low attack-incidence on case-mortality, as well as to ascertain whether case-mortality tends to vary with the advance of an epidemic.

The chart shows the deaths occurring in each quarter of the year, stated as percentages of the cases notified in the same quarter; it also exhibits the attack-incidence, stated per 1,000 of population, for each quarter.

A defect in the construction of Chart VI, as already noted, is that the deaths occurring during a given quarter do not correspond exactly with the cases reported during the same period, as certain of the deaths at the beginning of the quarter are of cases reported in the previous quarter, and some of the cases at the end of the quarter terminate fatally in the following quarter; but as measles is not usually a disease of long duration, and the chart periods are quarterly, any error arising from this is probably not great.

On examining the epidemics individually with respect to the relationship between extent of epidemic and height of case-mortality, no general law is seen to emerge, although, on the whole, it would appear as if a large epidemic was usually associated with a low case-mortality, and a small epidemic with a high case-mortality; but there are several exceptions.

In comparing the progress of an epidemic with changes in casemortality, it will be found to be the usual rule that the case-mortality increases greatly during the decline of the epidemic; but this increase does not necessarily imply a corresponding increase in the virulence of the cases, as the increase may be partly due to deaths of cases notified 
in a preceding quarter, when the cases were, in point of number, at their height. But after allowing for this, it can scarcely be doubted that the chart seems to prove a real rise in the case-mortality during the decline of the epidemic. It has, however, to be noted that this rise has been much less apparent in the more recent epidemics.

The times of the very highest case-mortality appear to occur during the inter-epidemic periods, when the cases of measles are few; but the excessive mortality may be partly fictitious, and due to relatively less complete notification of cases than in epidemic times.

\section{IV.-Case Mortality in Relation to Size of House. (Chart X.)}

Chart X. has been prepared for the purpose of demonstrating the influence of social condition on the case-mortality of measles. The size of the house in each case being obtainable from the records of the Sanitary Department, and, being a fair criterion of social conditions, forms the basis of the classification in this chart.

The different houses have been classified, according to the number of rooms, into five groups; and the cases and deaths occurring in each group are given. The average number of inmates in each group of houses is also stated.

The fifth group-five rooms and over-includes all institutions, hotels, etc., except the Hospitals and Infirmaries. Cases occurring in these institutions are not included. Cases removed to such institutions for treatment are, of course, classed with the size of house from which they were removed. It was thought to be unfair to the class of larger houses to include infirmaries, as cases occurring in such institutions-e.g., the Sick Children's Hospital-attack children already weakened by other diseases, and the case-mortality is thus greatly raised.

As an alternative such eases might have been referred back to the class of house from which they originally came, but the difficulty of tracing the house was great, especially in cases from the Children's Hospital, many of which had come from the country. Accordingly in Chart X. both cases and deaths in such institutions have been omitted, thus relieving houses, probably of the first and second classes, of a little of their proper mortality. The results seen in Chart $\mathrm{X}$. are striking. The average case-mortality from measles for all houses taken together amounted to $2 \cdot 4$ per cent., but in one-roomed houses it was 6.8 per cent, or almost three times as great as the average; while in houses of four rooms and houses of five rooms and upwards it was barely 1 per cent, or only about one-third of the average. In other words, among those attacked by measles; for every child that 
Aberdeen.

ChartX.

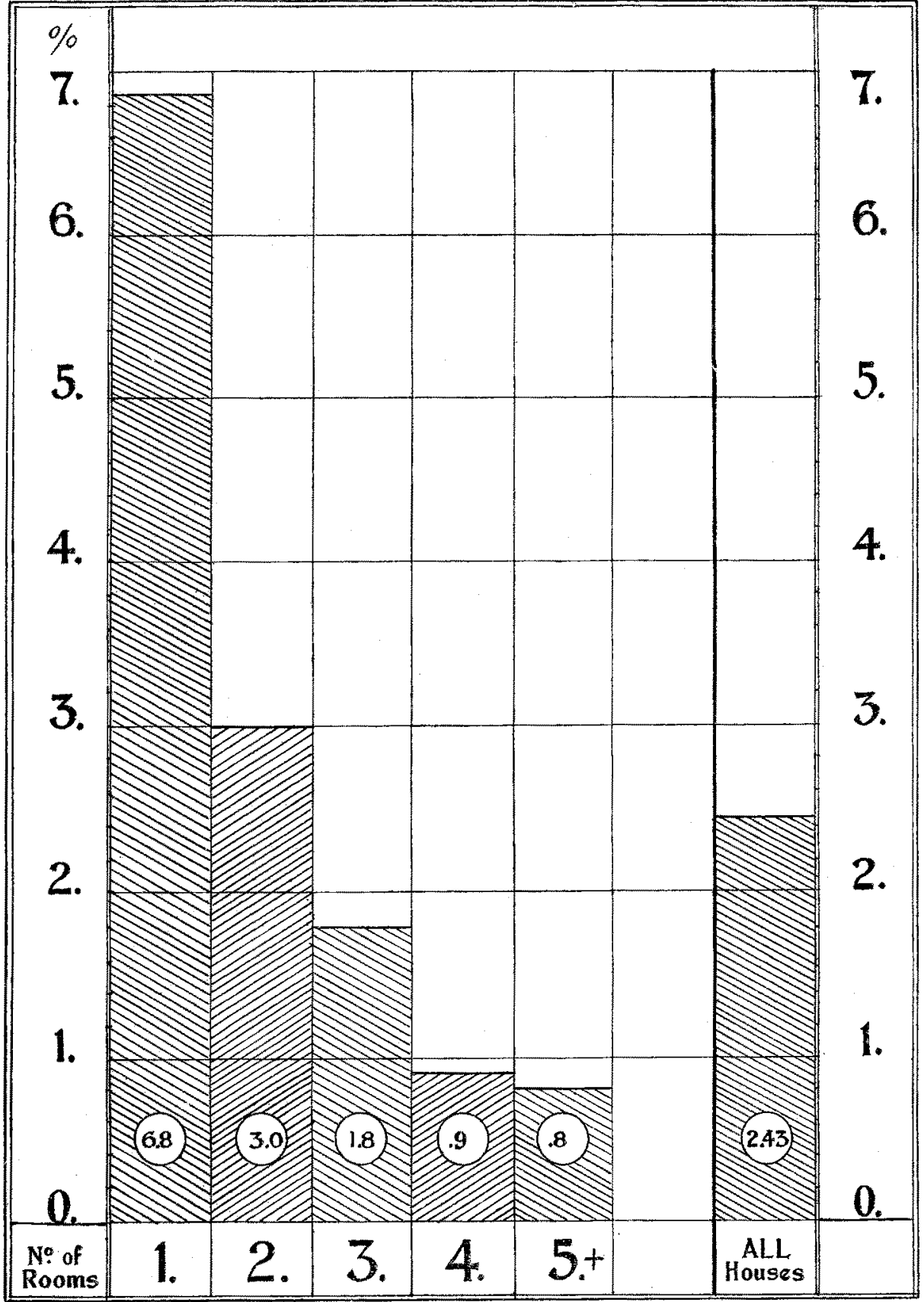

\begin{tabular}{|c|c|c|c|c|c|c|}
\hline CASES & 1067 & 11464 & 6779 & 2046 & 2675 & 24031 \\
\hline DEATHS & 73 & 348 & 122 & 19 & 22 & 584 \\
\hline $\begin{array}{l}\text { AVERAGE HO } \\
\text { i MMATES. }\end{array}$ & 4.1 & 5.2 & 5.8 & 6.2 & & \\
\hline
\end{tabular}

MEASLES- Case Mortality in different sizes of houses. (1893-1902) (Per 100 Cases notified) 
Aberdeen

Chart XI.

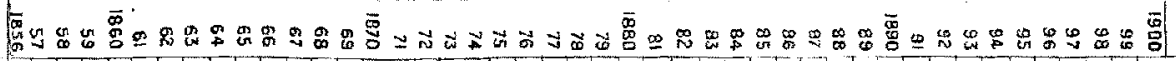

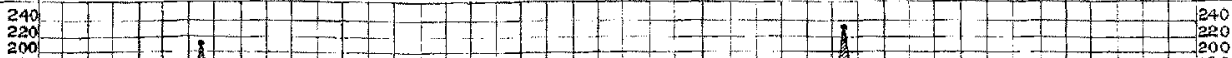
(20)

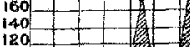

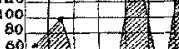

ABERDEEN

${ }_{30}^{40} y_{12}=1$,

14001 $1 \div-1+1$ , 管

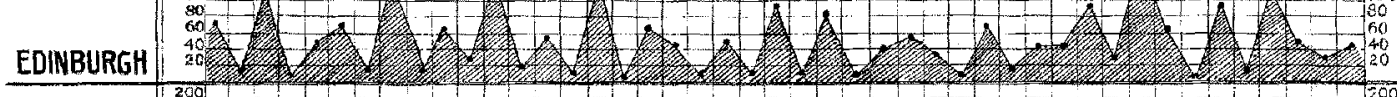

GLASGOW

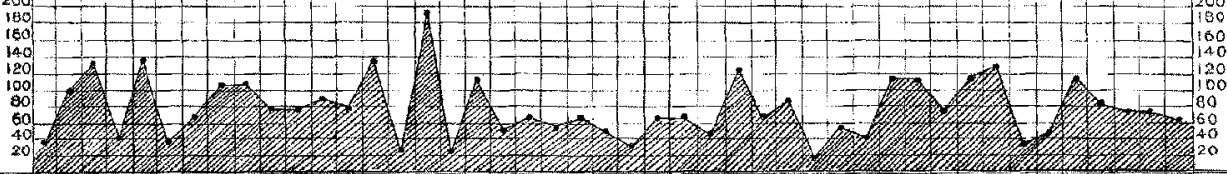

DUNDEE

GREENDCK

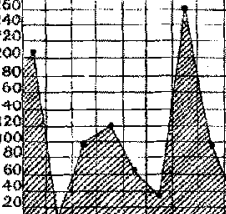

$\frac{320}{3000}$

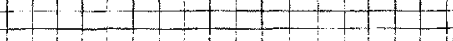

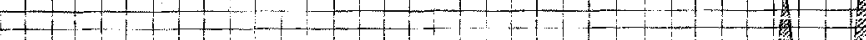

$10+1+2$

PAISLEY

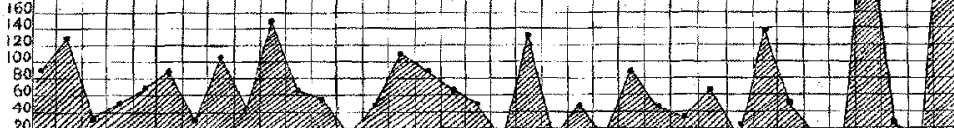
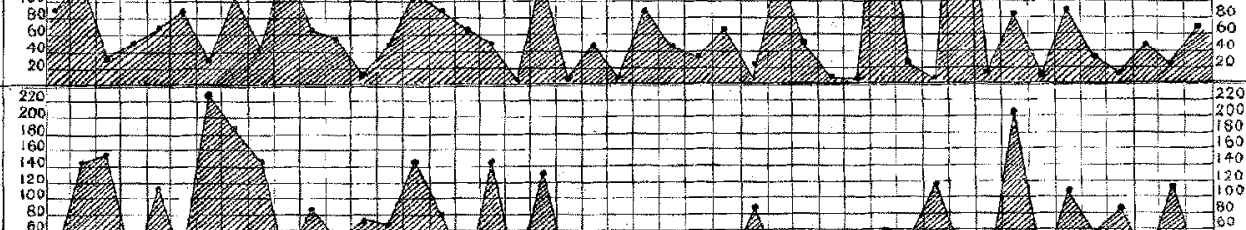
${ }^{40} \cdot 0$ -

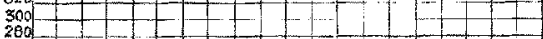

$\frac{260-}{242}$

200

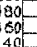

$F+$

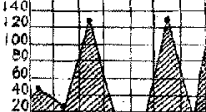

LEITH 20.3.

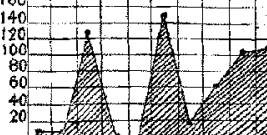

PERTH

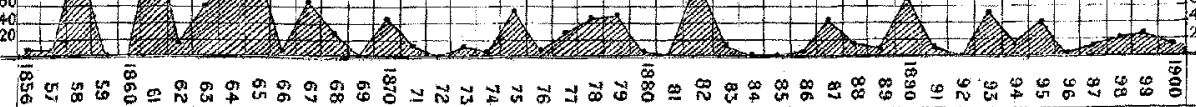

MEASLES.- Annual Mortality per 100,000 of Population in eight towns in Scolland, from 1855 fol 1900. (45 years). 
died in a four or five-roomed house, about seven children died in oneroomed houses. The mortality among measles patients in two-roomed houses was 3.0 per cent, or rather less than half the rate in one-roomed houses; and in three-roomed houses it was 1.8 per cent, or exactly twice as high as in four-roomed houses.

A comparison with a similar chart for whooping-cough, prepared by the late Dr. James S. Laing, shows a like result, although the fall in the case-mortality in larger houses is not so marked. The figures for whooping cough were-in one-roomed houses, a case-mortality of 7.8 per cent; in two-roomed houses, 4.5 per cent; in four-roomed, 3.4 per cent; in houses of five rooms and upwards, $2: 2$ per cent; and for all houses the percentage of deaths was 4.7 per cent, thus, apparently, showing that whooping-cough is somewhat less amenable to improved social conditions than measles.

\section{Complidations of Measles.}

In Table III. will be found an analysis of over 24,000 cases of measles, showing the complications registered as occurring in 619 fatal casesthe cases being arranged according to age. An attempt was made to ascertain the average duration of fatal cases, but owing to the frequent absence of information as to the duration in the death certificate, and to the extreme variability of the duration. where stated, it was thought that the results would not justify the labour.

It will be seen that $15 \cdot 6$ per cent of all deaths from measles were reported as uncomplicated; that 22 per cent were complicated with broncho-pneumonia ; 16 per cent with acute pneumonia; 16 per cent with bronchitis ; 4 per cent with tubercular meningitis; and 1.2 per cent with other tubercular diseases. In 12 per cent the complication was convulsions.

Where more than one complication was stated in the death certificate the primary complication is taken as the basis of the classification.

It is interesting to observe that broncho-pneumonia as a complication was most frequent among children of the age of four, and least common among infants under one year. Acute pneumonia was about equally common at all ages. Acute bronchitis, differing from broncho-pneumonia, was least common at the age of four, and most common at the school age-period.

Among other complications, meningitis was most common during the first year of life. Gastro-intestinal diseases were most frequent during the second year, and much less frequent during the first year. Convulsions were by far most common among infants under one year. 
Comparison of Aberdeen wrmh other Scottish Towns in Respect of Mortality from Measles. (1856-1900.)

\section{(Chart XI.)}

Chart XI. shows in graphic form the annual mortality from measles per 100,000 of population in eight of the principal towns of Scotland since 1856, or the year following the commencement of the civil registration of deaths. The accompanying table gives the average annual mortality from measles in each town for three component periods, viz.-1856 to 1872,1873 to 1887 , and 1888 to 1900 .

It will be observed that the towns differ very considerably in their total average mortality for the whole period. Glasgow is the highest, with 78 per 100,000 , Paisley and Greenock come next, with 67 and 65, and are followed, in order, by Leith with 57 , Dundee with 55 , Aberdeen with 52, and Edinburgh with 50. Perth, with 30, has distinctly the lowest mortality for the whole period.

AVERAGE ANNUAL MORTALITY FROM MEASLES, PER 100,000 OF POPULATION.

\begin{tabular}{lll|c|c|c|c}
\hline & & 1856 to 1872 & 1873 to 1887 & 1888 to 1900. & 1856 to 1900. \\
\hline Aberdeen & $\ldots$ & $\ldots$ & 61 & 44 & 51 & 52 \\
Edinburgh & $\ldots$ & $\ldots$ & 52 & 39 & 58 & 50 \\
Glasgow & $\ldots$ & $\ldots$ & 86 & 64 & 82 & 78 \\
Dundee & $\ldots$ & $\ldots$ & 83 & 34 & 44 & 55 \\
Paisley & $\ldots$ & $\ldots$ & 73 & 47 & 81 & 67 \\
Greenock & $\ldots$ & $\ldots$ & 92 & 35 & 66 & 65 \\
Leith & $\ldots$ & $\ldots$ & 56 & 42 & 75 & 57 \\
Perth & $\ldots$ & $\ldots$ & 43 & 22 & 22 & 30 \\
& & & & & & 56 \\
\hline
\end{tabular}

Aberdeen, therefore, if Perth be excepted, occupies one of the lowest positions. It is interesting to note that, excluding Perth, the four towns with the lowest mortality are all situated on the east coast, while the three highest are on the west coast, or very near to it. Within the last twelve years, however, the mortality in Leith has risen to the west coast level.

On the whole, it cannot be said that there is any general rise or fall of the mortality in the selected towns. In some-if the comparison is restricted to the earliest and latest periods-there is practically no change--e.g., in Edinburgh and Glasgow; in others, such as Dundee, Perth, and Greenock, there is a large fall, while in Leith there is a large rise. In Aberdeen there has been a moderate fall.

An examination of Chart XI. gives an impression of three different periods of epidemic prevalence and mortality the first, consisting of 
a succession of high mortality peaks, the second of low peaks, and the third of high peaks again. This is common to all the towns represented in the chart, with the exception of Perth, which shows no rise in the third period with high peaks.

This cyclical change is not equally well defined in all the towns. In some the succession of low peaks seems to begin earlier, and, in others, later. The table of figures confirms the impression derived from the chart.

In comparing the charts for the several towns, one is struck by the almost constant epidemicity of measles in Glasgow-that is, in by far the most populous town; while in the smallest town-Perth-the epidemic peaks are wider apart than anywhere else. In Aberdeen the interval between the epidemic peaks is almost always two or three years. In Perth it extends not infrequently to four or five years. Generally, the larger the town, the greater is the tendency to frequency of epidemics.

An interesting question is whether the peaks in the different towns coincide in such a manner as to suggest any generally operative influence, atmospheric or otherwise, which might assist or determine the simultaneous occurrence of measles epidemics.

A careful comparison of the towns in the chart shows that, except in the case of Leith and Edinburgh, which practically form one town, no synchronism of peaks is to be found. Such towns as Paisley and Greenock, Dundee and Perth, though close to each other, show very little correspondence in the recurrence of their epidemics of measles.

The one appearance in the chart more or less common to all is what has already been spoken of as possibly indicating a long-period prevalence or mortality wave; and this, being a mortality curve, may indicate a gradual change in severity of type, such as has been frequently remarked for scarlet fever, rather than a change in prevalence due to climatic or other causes.

\section{SUMmary. \\ Attack-Incidence (Morbidity).}

1. So far as the notification records for the past twenty years show, the prevalence of measles in Aberdeen has apparently increased considerably during the last ten years, 1892 to 1902 (Chart I.), but this is probably in part due to increased efficiency in notification. A review of the mortality since 1856 points to the prevalence being as great for some years after 1856 .

2. The numerical intensity of measles epidemics at their height has on the whole increased throughout the past twenty years, as seen from 
(hart $I$., but this also may be in part, if not altogether, due to more complete notification.

3. The epidemic periodicity in Aberdeen, is chiefly biennial though sometimes triennial. In still larger towns the tendency to a short periodicity is still more pronounced (Charts I. and XI.).

4. There appears to be a periodicity among the epidemic years themselves, indicated by a rise at every third epidemic (Chart I. and Table I.).

5 . There is also the suggestion of a still wider cyclical change in the form of a prevalence wave covering a period of about 12 to 15 years (Chart XI.).

6. Measles in Aberdeen is most prevalent in the cold months of winter and spring, and least prevalent in late summer and early autumn (Chart II.).

7. The attack-incidence is highest among children in the second to the seventh years of life (Chart III.). In the first and eighth years of life it is, roughly, only about a half of the incidence at the years stated. After the eighth year it rapidly falls.

8. Females appear to be slightly more liable than males to measles, the difference being most marked in the third and fourth years of life (Chart IV.).

9. Second attacks occurred in about $2 \frac{1}{2}$ per cent of the notified cases, and were more frequent in females than males, except between the ages of fifteen and twenty-five years. Second attacks are rare at ages above twenty-five years. Third attacks occurred in fully 2 per cent of the cases of second attack, and were more frequent at the later than the earlier ages. Confusion in diagnosis between measles and German measles may invalidate these conclusions.

10. Epidemics of measles and whooping cough alternate with considerable regularity-measles following upon whooping cough, rather than whooping cough on measles (Chart I.).

\section{Mortality.}

11. In Aberdeen, the average annual mortality from measles during the past ten years has fallen considerably, having dropped from $62 \cdot 4$ per 100,000 of population in 1883-1892 to 43.0 in 1893-1902. In the periods preceding 1883 the rate was, from 1856 to 1872,61 per 100,000 of population, and from 1873 to 1887 it was 44 (Charts V. and XI.).

\section{Case-Mortality.}

12. The case-mortality in Aberdeen during the twenty years of notification has fallen greatly, viz. : from $5 \cdot 3$ per cent in the first five years, to 1.9 per cent in the last five years (Chart VI.); but the fall 
may be in part more apparent than real, due to increasing efficiency of notification.

13. The case-mortality shows three maxima in the course of the year in April, July, and November, the highest being in April-with a decided minimum in September (Chart VII.).

14. The case-mortality is highest, by far, in the first and second year of life, and highest of all in the fourth quarter of the first year of life (Charts VIII. and IX.). It is, therefore, of great importance to protect children from measles during these years.

15. The average case-mortality at all ages, taken together, is slightly higher in males than in females, and is especially so in the first three years of life (Chart IX.).

16. The case mortality does not exhibit any definite relationship to the size of an epidemic. It tends, however, to increase with the progress of an epidemic, and is much higher at the end than the beginning. It is usually highest of all in the intervals between epidemics (Chart VI).

17. The ease-mortality is very markedly affected by social conditions, as determined by the size of house. The smaller the house, the greater is the case-mortality (Chart X.).

\section{Comparison of the Principal Scottish Towns in Respect of Mortality from Measles (1856 to 1900).}

(Chart XI.)

18. The towns differ considerably in their average mortality rate from measles during this period, the average mortality in the most populous town-Glasgow-being fully two and a half times as great as in the least populous town-Perth.

19. There are eonsiderable differences between the towns in the progress of the mortality rate. In the two largest towns the rate is practically stationary. In the other towns, except Leith and Paisley, it has fallen.

20. The larger the town, the shorter, on the whole, is the periodicity of epidemic prevalence-the periodicity showing a tendency to be biennial and, occasionally, triennial.

21. There is no evidence of the epidemicity being determined by atmospheric or similarly wide-spread conditions. It is probably determined for the most part by the accumulation of susceptible material.

Note on Dr. Wilson's Paper on Measles in Aberdeen.-Prof. Hay writes: The chief lessons of the analysis are, perhaps, three-First, that, in a town like Aberdeen, the vast majority of children take measles before they reach the age of nine, and that it may be assumed for questions 
of school attendance that there is little danger to others in allowing children from measles-infected houses to continue at school if their classmates are of the age of eight and upwards; second, that the disease is greatly more fatal during the first and second years of life, and, in a less degree, during the third year, than in later years, and that it is, therefore, of great importance to use the utmost efforts to protect children from infection during the first three years of life ; and, third, that the mortality is greatly heightened by inferiority of social condition, as measured by the size of the house in which the family of the patient resides. The results generally of the investigation are very similar to those obtained by Dr. Laing in his investigation of whooping cough.

Water Works AND AGriculture.-The undeniable fact of the general sinking of the level of the water in the chalk and gravels of the London Basin north of the Thames, especially from the Chiltern Hills to Epping Heights, has been naturally ascribed to the pumping operaions of the various water companies. Twenty years ago two-thirds of the water supplied by the New River Co. and practically the whole of that of the East London, was drawn from the river Lea, whereas the former now often refrains for weeks from using that source, and the East London has followed the example of its neighbour in extensive well sinking. Meanwhile private wells, except those in the clay which have no connection with the underlying chalk, have to be sunk deeper and deeper to follow the retreating water, while ponds and streams are drying up. The directors indeed deny their responsibility, ascribing these effects wholly to a long series of years in which the rainfall has been below the average, and point to the fact that a similar deficiency with its consequences has been felt elsewhere. But cycles of low rainfall have followed one another in the past without having necessitated the deepening of wells, and the fact of water famines having been felt elsewhere proves nothing, or if they could. be ascribed to like conditions might support the position of the complainants. But we now have complaints of a precisely similar character from Holland, where four-fifths of the towns are supplied from wells, more or less deep, the whole country being an alluvial plain, without any mountains or upland moors where the rainfall and streams as yet uncontaminated might be impounded. In former days the inhabitants of the towns depended on rivers and shallow wells as the rural population does now, but though in the absence of sewage, all exereta being applied directly to the land, very little enteric fever results from the use of such questionable supplies, the towns have rightly come to look on them as dangerous. The result has been what those who refuse to believe in alleged "inexhaustible" subterranean reservoirs would have predicted. The Dutch farmers, who are the most important and wealth-producing part of the nation, declare that their wells are failing, and that the arable land and the pastures, save where the proximity of a river or dyke gives facilities for irrigation, are suffering from the effects of chronic drought. The rain falls, but percolates rapidly downwards through the dry, light soil, while the depth of the ground water from the surface is such that capillary attraction fails to raise the moisture within reach of the roots. Such underground collections of water as that resting on the gault and green sands or other impervious strata beneath London, are undoubtedly vast, having been accumulating for ages, but not inexhaustible; and if the volume abstracted annually be in excess of that portion of the rainfall that is added to it, its exhaustion is simply a matter of time. 